\title{
Comparative assessment of commercial ELISA kits for detection of HIV in India
}

\author{
Srijita Nandi, Susmita Maity, Somesh Chandra Bhunia and Malay Kumar Saha*
}

\begin{abstract}
Background: India harbors the $3^{\text {rd }}$ highest HIV infected population globally. The magnitude of the HIV detection challenge is enormous. ELISA is the most commonly used screening technique for HIV. There is always an acute need for good quality ELISA kits. However, the quality evaluation data on Indian kits are very limited in comparison with internationally recognized kits. This study aimed to evaluate the performance and diagnostic usefulness of five commercially available ELISA kits which are frequently used in India.

Findings: The ELISA kits evaluated using an in-house well characterized 100 member sera panel revealed 100\% sensitivity for all the batches. However, batch to batch variation in terms of specificity, positive predictive value (PPV) and efficiency, although not statistically significant ( $p>0.05$ ), was observed. For specificity, the $3^{\text {rd }}$ generation kits (mean $99.6 \%$ to $99.3 \%$ ) were comparatively better than the $4^{\text {th }}$ generation assays (97.2\% to $96.9 \%$ ). But the $4^{\text {th }}$ generation kits performed far better in the ability for early detection post HIV infection in the 25 member commercial seroconversion panel with a margin of at least 22 days and as high as 35 days than the $3^{\text {rd }}$ generation assays.

Conclusions: The commercial ELISA kits with 100\% sensitivity seem appropriate for HIV screening. The ability of early detection post HIV infection favors use of $4^{\text {th }}$ generation kits for ensuring HIV free blood for transfusion. Lot to lot variations, especially kits having the specificity level $\leq 98.0 \%$, indicate the need for a regular mechanism of kit evaluation for each batch for procuring kits appropriate for intended use.
\end{abstract}

Keywords: HIV, ELISA, Sensitivity, Specificity, Efficiency, Sera panel, Seroconversion panel

\section{Findings}

\section{Background}

HIV is a major global public health issue [1]. For assuring a safe blood supply and preventing HIV infection, proper and accurate detection of HIV is essential [2]. In India, diagnosis of HIV infection is a major challenge $[3,4]$. Several commercial assays are available for detection of HIV infection. ELISA is the most commonly used screening assay for HIV [2,5]. A number of ELISA kits for HIV detection with different principles are available. Nowadays, in India $3^{\text {rd }}$ generation ELISA are most commonly used. The $4^{\text {th }}$ generation assays are based on combined detection of antigen and antibodies simultaneously and reduce the diagnostic window period further, compared to third generation ELISA which is based on antiHIV antibody assay [6-8]. The improved sensitivity for ELISA is mostly accompanied by a decreased specificity.

\footnotetext{
*Correspondence: sahamk@yahoo.com

National HIV Reference Laboratory, National Institute of Cholera and Enteric Diseases, Beliaghata, 700010 Kolkata, India
}

In an Indian perspective, limited articles on evaluation and performance of ELISA kits are available [9] though HIV testing is being done for a vast numbers of individuals as well as large number of specimens for ensuring HIV free safe blood for transfusion. Being the $2^{\text {nd }}$ most populous country with the $3^{\text {rd }}$ largest burden of HIV in the world [10], the magnitude of HIV testing challenge in India is enormous and the appropriate response to the challenge is to ensure the quality of the assay kits suitable for the intended use. This study aims to evaluate the quality of commonly available commercial ELISA kits for their ability to detect HIV suitable for appropriate use in India.

\section{Materials and methods}

The study was carried out at a National HIV Reference Laboratory designated for evaluation of diagnostic kits, including ELISA, in India. A well characterized, 100 members, in-house HIV serum panel was used to evaluate and compare the performance of the kits. The sera used for 
Table 1 Details of kits used for characterization of in-house panel sera

\begin{tabular}{|c|c|c|c|c|c|}
\hline \multirow{2}{*}{$\begin{array}{l}\text { Source of } \\
\text { sample }\end{array}$} & \multirow{2}{*}{$\begin{array}{l}\text { Name of } \\
\text { panel }\end{array}$} & \multicolumn{4}{|c|}{ Test details } \\
\hline & & ELISA 1 & ELISA 2 & Rapid test & Confirmatory test \\
\hline \multirow[t]{8}{*}{ ICTC } & \multirow[t]{8}{*}{$\begin{array}{l}\text { HIV Sera Panel } \\
\text { (In-house) }\end{array}$} & Genetic Systems & Genedia HIV Ag-Ab ELISA & Rapid 1: Determine HIV1/2 & $\begin{array}{l}\text { Recombinant } \\
\text { Immunoblot Assay }\end{array}$ \\
\hline & & HIV-1/HIV-2 & \multirow{2}{*}{$\begin{array}{l}\text { Green Cross Life } \\
\text { Science Corp. Korea }\end{array}$} & \multirow{2}{*}{$\begin{array}{l}\text { Inverness Medical } \\
\text { Japan Co. Ltd. Japan }\end{array}$} & \multirow[t]{2}{*}{ Chiron RIBA HIV-1/HIV-2 SIA } \\
\hline & & Plus O EIA. & & & \\
\hline & & \multirow[t]{2}{*}{ Bio-Rad Laboratories. USA } & \multirow{2}{*}{$\begin{array}{l}\text { Reactivity range } \\
\text { (pos specimens): } 3.503-8.899\end{array}$} & \multirow[t]{2}{*}{ Rapid 2: HIV TRI-DOT + Ag } & Ortho Clinical \\
\hline & & & & & Diagnostics Ltd, USA \\
\hline & & \multirow[t]{2}{*}{ Reactivity range } & & \multirow[t]{2}{*}{ J. Mitra \& Co. Pvt. Ltd. India } & AMPLICOR HIV-1 DNA Test \\
\hline & & & & & Version 1.5 \\
\hline & & $\begin{array}{l}\text { (pos specimens): } \\
3.485-10.017\end{array}$ & & & $\begin{array}{l}\text { Roche Molecular } \\
\text { Systems Inc. USA }\end{array}$ \\
\hline
\end{tabular}

preparing the in-house panel were obtained anonymously from attendees of the Counseling and Testing Centre by taking informed consent as per the protocol approved by Institutional Ethical Committee of National Institute of Cholera and Enteric Diseases. Beside the negative and positive sera, this serum panel also contained low positive sera that have shown uniform results in all assays used for validation. The characterization of in-house panel was done using United States Food and Drug Administration (U.S. FDA) or Indian Central Drug Standard Control Organization (CDSCO) approved kits (Table 1). Samples non-reactive for all assays were defined as negative and reactive for all assays were defined as positive member in the panel. A commercial seroconversion panel (Lot\# RP-018, Bio-Rad Laboratories, U.S.A) used to evaluate kits consists of a series of 25 specimens collected from an individual infected with HIV undergoing seroconversion.
Five batches each of 5 commonly available commercial ELISA kits, including $3^{\text {rd }}$ and $4^{\text {th }}$ generations, for HIV detection were evaluated (Table 2). All the kits were tested and results were validated strictly adhering to manufacturers' instruction. The evaluation process maintained an unbiased method following a double blind procedure by using different personnel for pre-analytical and analytical testing sections. The final analysis of results with interpretation was done by the laboratory in-charge. The status of samples was unknown to the persons involved in pre-analytical and analytical procedures. The performance of kits was evaluated and compared in terms of sensitivity $([\mathrm{TP} /(\mathrm{TP}+\mathrm{FN})] \times 100)$, specificity $([\mathrm{TN} /(\mathrm{TN}+\mathrm{FP})] \times 100)$, positive predictive value $(\mathrm{PPV}=[\mathrm{TP} /(\mathrm{TP}+\mathrm{FP})] \times 100)$, negative predictive value $(\mathrm{NPV}=[\mathrm{TN} /(\mathrm{TN}+\mathrm{FN})] \times 100)$ and efficiency $([(\mathrm{TP}+\mathrm{TN}) /(\mathrm{TP}+\mathrm{FN}+\mathrm{TN}+\mathrm{FP})] \times 100)$, where $\mathrm{TP}=$ number of true positives, $\mathrm{TN}=$ number of true negatives, $\mathrm{FP}=$ number of false positives and $\mathrm{FN}=$ number

Table 2 Performance of HIV ELISA kits with In-house Sera Panel

\begin{tabular}{|c|c|c|c|c|c|c|c|c|c|c|c|c|}
\hline \multirow{4}{*}{$\begin{array}{l}\text { Total no. of samples } \\
100 \\
\text { (Confirmed Positive }=40 \\
\text { Confirmed Negative }=60 \text { ) }\end{array}$} & \multirow{2}{*}{\multicolumn{2}{|c|}{$\begin{array}{l}\text { Total no. of } \\
\text { lots evaluated } \\
5 \text { Lots }\end{array}$}} & \multicolumn{10}{|c|}{ Kit performance } \\
\hline & & & \multirow{2}{*}{\multicolumn{2}{|c|}{$\begin{array}{l}\text { J. Mitra \& } \\
\text { Co. Pvt. Ltd. } \\
\text { Assay result }\end{array}$}} & \multirow{2}{*}{\multicolumn{2}{|c|}{$\begin{array}{l}\text { Span Diagnostics Ltd. } \\
\text { Assay result }\end{array}$}} & \multirow{2}{*}{\multicolumn{2}{|c|}{$\begin{array}{c}\begin{array}{c}\text { Transasia } \\
\text { Bio-medicals } \text { Ltd. }\end{array} \\
\text { Assay result }\end{array}$}} & \multirow{2}{*}{\multicolumn{2}{|c|}{$\begin{array}{l}\text { Bio-Rad Laboratories. } \\
\text { Assay result }\end{array}$}} & \multirow{2}{*}{\multicolumn{2}{|c|}{$\begin{array}{l}\text { Biomerieux. } \\
\text { Assay result }\end{array}$}} \\
\hline & \multicolumn{2}{|c|}{ for each kit } & & & & & & & & & & \\
\hline & & & Pos & $\mathrm{Neg}$ & Pos & $\mathrm{Neg}$ & Pos & $\mathrm{Neg}$ & Pos & $\mathrm{Neg}$ & Pos & Neg \\
\hline & Lot:1 & Pos & 40 & 00 & 40 & 01 & 40 & 00 & 40 & 02 & 40 & 02 \\
\hline & & Neg & 00 & 60 & 00 & 59 & 00 & 60 & 00 & 58 & 00 & 58 \\
\hline & Lot:2 & Pos & 40 & 01 & 40 & 00 & 40 & 00 & 40 & 02 & 40 & 02 \\
\hline & & Neg & 00 & 59 & 00 & 60 & 00 & 60 & 00 & 58 & 00 & 58 \\
\hline & Lot:3 & Pos & 40 & 00 & 40 & 00 & 40 & 00 & 40 & 01 & 40 & 01 \\
\hline & & Neg & 00 & 0 & 00 & 60 & 00 & 60 & 00 & 59 & 00 & 59 \\
\hline & Lot:4 & Pos & 40 & 01 & 40 & 00 & 40 & 00 & 40 & 01 & 40 & 03 \\
\hline & & Neg & 00 & 59 & 00 & 60 & 00 & 60 & 00 & 59 & 00 & 57 \\
\hline & Lot:5 & Pos & 40 & 00 & 40 & 01 & 40 & 01 & 40 & 02 & 40 & 01 \\
\hline & & Neg & 00 & 60 & 00 & 59 & 00 & 59 & 00 & 58 & 00 & 59 \\
\hline
\end{tabular}


of false negatives [11]. Confidence Interval (CI) was used to address precision of the proportion estimates and the degree of confidence was set to 95\% [12]. Chi-square analysis was performed to assess the variation for specificity, PPV and efficiency among different kits as well as in different batches of same kit.

\section{Results}

None of the ELISA kits evaluated was able to identify all the panel members correctly by all the batches (Table 2 ). But all the kits were found to be $100 \%$ sensitive in all the batches. Variation in batches of all the kits was evident in terms of specificity, PPV and efficiency (Table 3). ERBA LISA HIV $1+2$ provided correct results in 4 batches by identifying all panel samples correctly with 99.8\% efficiency. Microlisa HIV and Enzaids HIV $1+2$ both performed equally by correct result only in 3 batches with $99.6 \%$ efficiency. The $4^{\text {th }}$ generation kits, Genscreen and Vironostika, showed the false positivity rates higher than the $3^{\text {rd }}$ generations, but the variations were not statistically significant in terms of specificity $(\chi 2=0.0683$, $\mathrm{df}=4, \mathrm{p}>0.05)$, PPV $(\chi 2=0.1253, \mathrm{df}=4, \mathrm{p}>0.05)$ and efficiency $(\chi 2=0.0230, \mathrm{df}=4, \mathrm{p}>0.05)$ of all batches of all the ELISA kits. The performance of the kits evaluated using seroconversion panel revealed that all the $3^{\text {rd }}$ generation kits showed equal sensitivity by detecting HIV positivity. In contrast, the $4^{\text {th }}$ generation kits, Genscreen (detected panel member 5, day 16) and Vironostika (detected member 7 , day 29) were significantly more sensitive and were able to detect HIV positivity 35 and 22 days earlier respectively than the $3^{\text {rd }}$ generation ELISA kits (Table 4).

\section{Discussion}

ELISA is the type of test most commonly used for detection of HIV particularly for large numbers of specimens

Table 3 Performance characteristic of HIV ELISA kits used for comparative evaluation

\begin{tabular}{|c|c|c|c|c|c|c|c|c|c|c|c|}
\hline \multirow[t]{3}{*}{ Kit Name \& Company } & \multirow[t]{3}{*}{ Lot } & \multicolumn{10}{|c|}{ Kit Performance } \\
\hline & & \multicolumn{2}{|c|}{ Sensitivity } & \multicolumn{2}{|c|}{ Specificity } & \multicolumn{2}{|r|}{ PPV } & \multicolumn{2}{|r|}{ NPV } & \multicolumn{2}{|c|}{ Efficiency } \\
\hline & & (\%) & $\begin{array}{l}\text { \%Mean } \\
(95 \% \mathrm{Cl})\end{array}$ & (\%) & $\begin{array}{l}\text { \%Mean } \\
(95 \% \mathrm{Cl})\end{array}$ & (\%) & $\begin{array}{l}\text { \%Mean } \\
(95 \% \mathrm{Cl})\end{array}$ & (\%) & $\begin{array}{l}\text { \%Mean } \\
(95 \% \mathrm{Cl})\end{array}$ & (\%) & $\begin{array}{l}\text { \%Mean } \\
(95 \% \mathrm{Cl})\end{array}$ \\
\hline \multirow{5}{*}{$\begin{array}{l}\text { Microlisa HIV Company: } \\
\text { J. Mitra \& Co. Pvt. Ltd. }\end{array}$} & 1 & 100 & 100 & 100 & 99.3 & 100 & 99.0 & 100 & 100 & 100 & 99.6 \\
\hline & 2 & 100 & $(100-100)$ & 98.3 & $(98.2-100.3)$ & 97.6 & $(97.5-100.4)$ & 100 & $(100-100)$ & 99.0 & $(98.9-100.2)$ \\
\hline & 3 & 100 & & 100 & & 100 & & 100 & & 100 & \\
\hline & 4 & 100 & & 98.3 & & 97.6 & & 100 & & 99.0 & \\
\hline & 5 & 100 & & 100 & & 100 & & 100 & & 100 & \\
\hline \multirow{5}{*}{$\begin{array}{l}\text { Enzaids HIV } 1+2 \text { ELISA Company: } \\
\text { SPAN Diagnostics Ltd. }\end{array}$} & 1 & 100 & 100 & 98.3 & 99.3 & 97.6 & 99.0 & 100 & 100 & 99.0 & 99.6 \\
\hline & 2 & 100 & $(100-100)$ & 100 & $(98.2-100.3)$ & 100 & $(97.5-100.4)$ & 100 & $(100-100)$ & 100 & $(98.9-100.2)$ \\
\hline & 3 & 100 & & 100 & & 100 & & 100 & & 100 & \\
\hline & 4 & 100 & & 100 & & 100 & & 100 & & 100 & \\
\hline & 5 & 100 & & 98.3 & & 97.6 & & 100 & & 99.0 & \\
\hline \multirow{5}{*}{$\begin{array}{l}\text { ERBA LISA HIV } 1+2 \text { Company: } \\
\text { Transasia Bio-medicals Ltd. }\end{array}$} & 1 & 100 & 100 & 100 & 99.6 & 100 & 99.5 & 100 & 100 & 100 & 99.8 \\
\hline & 2 & 100 & $(100-100)$ & 100 & $(98.7-100.4)$ & 100 & $(98.3-100.6)$ & 100 & $(100-100)$ & 100 & $(99.3-100.2)$ \\
\hline & 3 & 100 & & 100 & & 100 & & 100 & & 100 & \\
\hline & 4 & 100 & & 100 & & 100 & & 100 & & 100 & \\
\hline & 5 & 100 & & 98.3 & & 97.6 & & 100 & & 99.0 & \\
\hline \multirow{5}{*}{$\begin{array}{l}\text { Genscreen Plus HIV Ag-Ab ELISA } \\
\text { Company: Bio-Rad Laboratories., U.S.A }\end{array}$} & 1 & 100 & 100 & 96.6 & 97.2 & 95.4 & 96.2 & 100 & 100 & 98.0 & 98.4 \\
\hline & 2 & 100 & $(100-100)$ & 96.6 & $(96.1-98.2)$ & 95.4 & $(94.8-97.5)$ & 100 & $(100-100)$ & 98.0 & $(97.7-99.0)$ \\
\hline & 3 & 100 & & 98.3 & & 97.6 & & 100 & & 99.0 & \\
\hline & 4 & 100 & & 98.3 & & 97.6 & & 100 & & 99.0 & \\
\hline & 5 & 100 & & 96.6 & & 95.4 & & 100 & & 98.0 & \\
\hline \multirow{5}{*}{$\begin{array}{l}\text { Vironostika HIV Ag/Ab Company: } \\
\text { Biomerieux SA. France }\end{array}$} & 1 & 100 & 100 & 96.6 & 96.9 & 95.4 & 95.8 & 100 & 100 & 98.0 & 98.2 \\
\hline & 2 & 100 & $(100-100)$ & 96.6 & $(95.3-98.4)$ & 95.4 & $(93.8-97.7)$ & 100 & $(100-100)$ & 98.0 & $(97.2-99.1)$ \\
\hline & 3 & 100 & & 98.3 & & 97.6 & & 100 & & 99.0 & \\
\hline & 4 & 100 & & 95.0 & & 93.4 & & 100 & & 97.0 & \\
\hline & 5 & 100 & & 98.3 & & 97.6 & & 100 & & 99.0 & \\
\hline
\end{tabular}


Table 4 Performance of HIV kits with Seroconversion Panel Sera (Lot\# RP-018)

\begin{tabular}{|c|c|c|c|c|c|c|}
\hline Panel member & Bleed day & $\begin{array}{l}\text { J Mitra \& Co. Pvt. Ltd } \\
\text { MICROLISA HIV } \\
\text { (S/Co) }\end{array}$ & $\begin{array}{c}\text { Span Diag. Ltd. } \\
\text { ENZAIDS HIV } 1+2 \\
(\mathrm{~S} / \mathrm{Co})\end{array}$ & $\begin{array}{c}\text { Transasia Bio-Medicals Ltd. } \\
\text { ERBALISA } \\
\text { (S/Co) }\end{array}$ & $\begin{array}{c}\text { Bio-Rad } \\
\text { GENSCREEN } \\
\text { (S/Co) }\end{array}$ & $\begin{array}{c}\text { Biomerieux } \\
\text { VIRONOSTICA } \\
\text { S/Co) }\end{array}$ \\
\hline 1 & 0 & 0.022 & 0.235 & 0.258 & 0.224 & 0.238 \\
\hline 2 & 3 & 0.007 & 0.162 & 0.183 & 0.221 & 0.15 \\
\hline 3 & 9 & 0.007 & 0.177 & 0.19 & 0.238 & 0.112 \\
\hline 4 & 13 & 0.015 & 0.148 & 0.171 & 0.238 & 0.254 \\
\hline 5 & 16 & 0.015 & 0.162 & 0.167 & 2.425 & 0.233 \\
\hline 6 & 20 & 0.007 & 0.162 & 0.171 & 2.888 & 0.258 \\
\hline 7 & 29 & 0.65 & 0.877 & 0.65 & 3.291 & 2.002 \\
\hline 8 & 51 & 6.723 & 4.401 & 3.806 & 9.396 & 2.265 \\
\hline 9 & 56 & 7.511 & 2.523 & 2.665 & 12.724 & 2.436 \\
\hline 10 & 58 & 7.285 & 3.65 & 4.182 & 14.224 & 2.967 \\
\hline 11 & 63 & 5.226 & 5.549 & 4.601 & 16.388 & 2.95 \\
\hline 12 & 65 & 7.635 & 5.069 & 5.247 & 17.993 & 3.245 \\
\hline 13 & 70 & 6.211 & 5.339 & 5.277 & 19.828 & 3.026 \\
\hline 14 & 72 & 6.073 & 6.419 & 5.787 & 20.91 & 4.513 \\
\hline 15 & 77 & 6.825 & 3.552 & 3.76 & 21.045 & 4.189 \\
\hline 16 & 79 & 7.182 & 4.639 & 4.95 & 22.425 & 4.472 \\
\hline 17 & 84 & 7.328 & 4.177 & 4.563 & 22.993 & 5.386 \\
\hline 18 & 86 & 7.81 & 3.953 & 4.19 & 22.037 & 5.729 \\
\hline 19 & 91 & 5.401 & 3.639 & 4.224 & 23.187 & 4.72 \\
\hline 20 & 93 & 7.606 & 3.964 & 4.285 & 23.575 & 5.604 \\
\hline 21 & 98 & 7.372 & 5.141 & 5.635 & 23.56 & 5.976 \\
\hline 22 & 100 & 6.467 & 3.469 & 3.798 & 24.007 & 5.988 \\
\hline 23 & 112 & 7.562 & 4.372 & 4.688 & 29.881 & 6.254 \\
\hline 24 & 114 & 7.993 & 3.776 & 4.213 & 24.91 & 6.537 \\
\hline 25 & 133 & 8.825 & 7.415 & 7.988 & 24.858 & 6.625 \\
\hline
\end{tabular}

$\mathrm{S} / \mathrm{Co}=$ Sample/cut of.

[2]. But the discordance between the results of different ELISA kits as well as in different lots of the same kit (particularly false positive rates), as evident in this study, highlights an important problem of potentially causing stress to falsely-positive individuals and may also lead to additional expenses $[13,14]$. Hence, evaluation of diagnostic ELISA kits gains importance for ensuring the availability of suitable kits with better performance in terms of recommended sensitivity and specificity [11], as in case of blood bank testing where a high degree of sensitivity is also recommended for choosing the testing kit [11]. Better performance, comparatively, was observed for ERBALISA kits with $100 \%$ efficiency in 4 out of 5 batches (mean efficiency 99.8\%). Microlisa and Enzaids each showed mean efficiency of $99.6 \%$. The performance of Genscreen and Vironostika was compromised in terms of specificity, PPV and efficiency as these kits give few false positive results. The PPV as estimated based on the composition of panel sera will change according to the prevalence in the targeted population to be tested [9]. Thus, in an Indian scenario with $0.27 \%$ HIV prevalence [15], the estimated PPV of the HIV ELISA kits would be $40.30 \%$ for both J.Mitra \& Co. Pvt. Ltd. and Span Diagnostics Ltd., $57.40 \%$ for Transasia Bio-Medicals Ltd. and $14.40 \%$ for Bio-Rad Laboratories. The performance of all five kits in terms of NPV favors their use as a primary screening assay for HIV infection. Unique combination of simultaneous Ag-Ab assay gives better performance in a seroconversion panel as well as reducing the testing window period by 3.82 days on average [6]. In this study, Genscreen and Vironostika, both $4^{\text {th }}$ generation assays, outperformed the $3^{\text {rd }}$ generation ELISA by reducing the window by 35 and 22 days respectively in the seroconversion panel. Genscreen showed better performance and identified early seroconversion than Vironostika in another study [16]. The $3^{\text {rd }}$ generation kits demonstrated 
efficiency ranging from 98.6 to $99.8 \%$. Though the efficiency of the $4^{\text {th }}$ generation assays is lower, the high sensitivity demonstrated by the kits may favor them for HIV screening purposes, because of their early detection by about 3 weeks post infection. Although lot to lot variation is evident in the study it is not statistically significant ( $p>0.05)$, but kits with specificity level $<98 \%$ are not recommended for diagnosis of HIV infection in India according to the national guideline [11].

The panel size is small with 100 members and one seroconversion panel only. Kit evaluation with small panel size may be valuable where studies are limited [17]. Use of a range of seroconversion panels is essential to test the biological differences in the timing of appearance of different antibodies to specific antigens in the host response to the various HIV antigens in a range of individuals. A more robust assessment requires the testing of, for example, 10 different seroconversion panels $[18,19]$.

\section{Conclusion}

With $100 \%$ sensitivity, both the $3^{\text {rd }}$ and $4^{\text {th }}$ generation commercial ELISA kits seem are appropriate as screening assay for detection of HIV infection. Earlier detection post HIV infection favors the use of $4^{\text {th }}$ generation kits for ensuring HIV free blood for transfusion. The lot to lot variation in terms of specificity warrants batch pre-acceptance testing of all new lots or batches of commercially available ELISA kits in India to ensure that new batches perform as well as previous ones.

\footnotetext{
Abbreviations

AIDS: Acquired Immuno Deficiency Syndrome; CDSCO: Central Drug Standard Control Organization; ELISA: Enzyme Linked Immunosorbent Assay; HIV: Human Immunodeficiency Virus; NPV: Negative Predictive Value; PPV: Positive Predictive Value; USFDA: United States Food and Drug Administration.

\section{Competing interests}

The authors declare that they have no competing interests.

\section{Authors' contributions}

All the authors conceived the study, SN, SM and SCB carried out the laboratory work, MKS analyzed and interpreted the data, SM performed the statistical analysis and all the authors contributed in drafting, and critically reviewed and approved the final manuscript.
}

\section{Acknowledgements}

We acknowledge NACO, New Delhi and West Bengal State AIDS Prevention and Control Society for partially supporting the study.

Received: 31 July 2013 Accepted: 1 July 2014

Published: 7 July 2014

\section{References}

1. Joint United Nations Programme on HIV/AIDS (UNAIDS): UNAIDS World AIDS Day Report. Switzerland: UNAIDS; 2011.

2. Beelaert $G$, Vercauteren $G$, Fransen $K$, Mangelschots M, Rooy MD, Garcia-Ribas S, Groen G: Comparative evaluation of eight commercial enzyme linked immunosorbent assays and 14 simple assays for detection of antibodies to HIV. J Virol Methods 2002, 105:197-206.

3. Ribeiro RR, Da Silva LF, Cunha CB, Cabral VP, Dietze R: Performance characteristics of a raid new immunochromatographic test for detection of antibodies to human immunodeficiency virus. Clin Diag Lab Immunol 2003, 10:303-307.

4. Iqbal HS, Solomon S, Murugavel KG, Solomon SS, Balakrishnan P: Evaluation of two indigenous rapid and two ELISA assays for the diagnosis of HIV infection India. Indian J Medical Microbio/ 2012, 30(4):397-402.

5. Crofts N, Maskill W, Gust ID: Evaluation of enzyme-linked immunosorbent assays: a method of data analysis. J Virol Methods 1988, 22:51-59.

6. Weber B, Berger A, Rabenau H, Doerr HW: Evaluation of a new combined antigen and antibody human immunodeficiency virus screening assay, VIDAS HIV DUO Ultra. J Clin Microbiol 2002, 40:1420-1426.

7. Ly TD, Laperche S, Couroucé AM: Early detection of human immunodeficiency virus infection using third- and fourth-generation screening assays. Eur J Clin Microbiol Infect Dis 2001, 20:104-110.

8. Saville RD, Constantine NT, Cleghorn FR, Jack N, Bartholomew C, Edwards J, Gomez P, Blattner WA: Fourth-generation enzyme- linked immunosorbent assay for the simultaneous detection of human immunodeficiency virus antigen and antibody. J Clin Microbiol 2001, 39:2518-2524.

9. Maity S, Nandi S, Biswas S, Sadhukhan S, Saha MK: Performance and diagnostic Usefulness of commercially available enzyme linked immunosorbent assay and rapid kits for detection of HIV, HBV and HCV in India. Virol J 2012, 9:290.

10. Alvarez-Uria G: Factors associated with delayed entry into HIV medical care after HIV diagnosis in a resource-limited setting: Data from a cohort study in India. Peer J 2013, 1:e90. e90 http://dx.doi.org/10.7717/peerj.90.

11. National AIDS Control Organization (Ministry of Health and Family Welfare Govt of India): Manual on Quality Standard for HIV Testing Laboratories. New Delhi: NACO; 2007.

12. Iqbal HS, Solomon S, Murugavel KG, Solomon SS, Balakrishnan P: Evaluation and diagnostic usefulness of domeatic and imported enzymelinked immunosorbent assays for detection of human immunodeficiency virus type 1 antibody in India. Clin Diagn Lab Immunol 2005, 12:1425-1428.

13. Matter L, Germann D: Detection of human immunodeficiency virus (HIV) type 1 antibodies by new automated microparticle enzyme immunoassay for HIV type 1 and 2. J Clin Microbiol 1995, 33:2338-2341.

14. Pyra H, Boni J, Schupbach J: Ultrasensitive retrovirus detection by a reverse transcriptase assay based on product enhancement. Proc Natl Acad Sci U S A 1994, 91:1544-1548.

15. National AIDS Control Organization (Ministry of Health and Family Welfare, Government of India): Technical Report India HIV Estimates. New Delhi: UNAIDS and NACO; 2012

16. Ly TD, Martin L, Daghfal D, Sandridge A, West D, Bristow R, Laurence C, Qiu X, Lou SC, Hunt JC, Schochetman G, Devare SG: Seven Human Immunodeficiency Virus (HIV) antigen-antibody combination assays: evaluation of HIV seroconversion sensitivity and subtype detection. J Clin Microbiol 2001, 39(9):3122.

17. Torane VP, Shastri JS: Comparison of ELISA and rapid screening tests for the diagnosis of HIV, hepatitis $B$ and hepatitis $C$ among healthy blood donors in a tertiary care hospital in Mumbai. Indian J Med Microbiol 2008, 26:284-285.

18. Perry KR, Ramskill S, Eglin RP, Barbara JA, Parry JV: Improvement in the performance of HIV screening kits. Transfus Med 2008, 18(4):228-240.

19. Barbara J, Ramskill S, Perry K, Parry J, Nightingale M: The National Blood Service (England) approach to evaluation of kits for detecting infectious agents. Transfus Med Rev 2007, 21(2):147-158.

doi:10.1186/1756-0500-7-436

Cite this article as: Nandi et al:: Comparative assessment of commercial ELISA kits for detection of HIV in India. BMC Research Notes 2014 7:436. 